B. С. Сторчак

Лётная академия Национального авиационного университета, Кропивницкий, Украина

\title{
ПРОБЛЕМЫ ПОДГОТОВКИ ДИСПЕТЧЕРОВ УПРАВЛЕНИЯ ВОЗДУШНЫМ ДВИЖЕНИЕМ
}

\begin{abstract}
Цель статьи. Определение направлений повышения эффективности профессиональной подготовки диспетчеров управления воздушным движением. В статье рассмотрены вопросы, связанные с проблемами подготовки диспетчеров управления воздушным движением. Обосновывается актуальность профессиональной подготовки и направления ее реализации. Анализируется профессиональная деятельность и состояние профессиональной подготовки диспетчеров управления воздушным движением. Определяются направления повышения эффективности базовой профессиональной подготовки, совершенствования и восстановления навыков в управлении экипажами при выполнении полетов в различных условиях. Предлагается новый подход к подготовке диспетчеров управления воздушным движением, который основан на использовании новых подходов к построению и использованию тренажерных комплексов и систем. Выводы. От того, насколько продумана такая подготовка и насколько хорошо продуман и проведен процесс обучения зависит уровень профессионального мастерства и безопасности полетов. В процессе подготовки должен предусматривается постоянный контроль действий операторов, в том числе процесс восприятия ситуации оператором, его осмысливания, формирования необходимых навыков, а также психофизиологического состояния оператора при решении им поставленной задачи. Дальнейшие исследования необходимо направить на создание и обоснование единой методологии построения тренажерных комплексов для обучения диспетчеров управления воздушным движением на основе использования новых информационных технологий.
\end{abstract}

Ключевы еслов а : АСУ, оператор, диспетчер УВД, тренажер, подготовка.

\section{Введение}

Надежность и своевременность принятия решений диспетчерами управления воздушным движением во многом определяется влиянием человеческого фактора. Профессиональная деятельность диспетчеров управления воздушным движением (далее операторов) может сопровождаться ошибками различной природы и характера. Они могут привести к возникновению авиационных инцидентов или происшествий.

Следовательно, вопрос анализа ошибочных действий операторов и вызвавших их психологических причин, методов и направлений их минимизации или устранения является актуальным.

Для анализа и классификации ошибок оператора введены следующие критерии: место ошибки в структуре эргатической системы, внешнее проявление ошибки, последствия ошибки, характер отображения ошибки в сознании оператора, причины ошибки. Рассмотренные ошибочные действия операторов классифицированы и сведены в три основные категории ошибок: процедурные, связи и управления оборудованием.

Исследования показывают, что больше половины ошибочных действий операторов и инцидентов классифицируется как «неграмотная» эксплуатация. Они совершаются из-за недостаточных знаний сущности процессов, происходящих во время работы системы, или недостаточного понимания последствий, вызываемых неправильными действиями оператора. Ошибки принятия решений обусловлены недостатками в формировании концептуальной модели управления, с трудностями актуализации необходимых в данный момент правил или инструкций. Повышение эффективности управления авиацией достигается путем постоянных тренировок с операторами на тренажерах.

\section{Постановка проблемы}

Современное состояние развития теории и практики образования, по мнению известных украинских ученых, характеризуется напряженным поиском путей актуального и прогнозируемого реагирования на вызовы времени. Непредсказуемость будущего, интенсивный рост высокотехнологичных производств, коммуникаций и человеческой географической и экономической мобильности, кризисы все это сказывается на качестве жизни в каждой стране [2].

Сегодня приходится констатировать, что социально экономические условия привели за последние 10 лет авиацию Украины к черте, за которой начинают проявляться необратимые процессы. Ситуация, в которой оказалась авиация Украины, привела к таким последствиям:

- снижение психологических показателей абитуриентов к выполнению работ по профессиональной направленности;

- существенное омоложение летных кадров, особенно среднего звена, которое имеет недостаточный практический опыт организации полетов;

- снижение мотивации к лётной работе и к управлению полетами авиации;

- снижение эксплуатационной надежности авиационной техники и её обслуживания по причинам морального старения, отсутствия запасных частей и недостаточной подготовки специалистов наземных служб выдвигает особые требования к подготовке диспетчеров управления воздушным движением по управлению полетами в аварийных ситуациях;

- наблюдается устойчивая тенденция резкого снижения интенсивности полетов, длительные перерывы в руководстве полетами, и как результат значительная потеря навыков практической работы летного состава. 
Такое состояние затрудняет процесс подготовки летного состава. Процесс подготовки операторов прямо пропорционально зависит от уровня подготовки летного состава, исправности авиационной техники, обеспеченности авиационным топливом и др., т.е. уменьшение интенсивности полетов приводит к снижению уровня умений и навыков летного состава, что негативно влияет на безопасность полетов. При этом остается задача поддержания уровня теоретической и практической подготовки операторов на грани не ниже допустимых значений.

Таким образом, для поддержания соответствующего уровня теоретической подготовки операторов необходимо сосредоточить главное внимание на тренажерной подготовке, её обеспечение методическим сопровождением, современными тренажерными системами и комплексами, что позволит поддержать и закрепить полученные знания, приобрести навыки и умения в управлении экипажами в сложной динамической навигационной обстановке и особых ситуациях.

Наиболее эффективным средством профессиональной подготовки операторов являются тренажеры, обеспечивающие искусственное воспроизведение условий и факторов, которые имеют место в процессе работы диспетчера по управлению реальным динамическим объектом.

В исследованиях последних лет проблемам создания и модернизации тренажерных комплексов различного назначения и методологическим принципам создания интегрированной учебно-тренировочной системы подготовки уделено внимание в работах $[1,3,4,6-8]$.

Система критериев оценки действий операторов и проблеме повышения качества профессиональной подготовки диспетчеров управления воздушным движением за счет реализации индивидуального подхода к обучению с использованием процедурных тренажеров рассмотрено в работах $[4,5]$. Принципы построения тренажеров различного назначения и эффективность их использования для профессиональной подготовки рассматривались в работах $[8,9]$.

Однако проблема совершенствования профессиональной подготовки операторов, в том числе с использованием тренажеров или тренажерных комплексов, при управлении авиацией и принятии решение в сложной в сложных ситуациях остается не решенной.

Кроме того, остаются не рассмотренными вопросы формирования компетентности операторов в процессе практической подготовки и роли тренажерной подготовки в системе профессионального обучение диспетчеров управления воздушным движением.

Цель статьи. Определение направлений повышения эффективности профессиональной подготовки диспетчеров управления воздушным движением.

\section{Основная часть}

Анализируя содержание профессиональной подготовки операторов определено, что их деятель- ность заключается в управлении экипажами с пунктов управления в своих зонах ответственности в сложных динамических обстановках.

Во время профессиональной подготовки операторов можно выделить два её вида - теоретическая и практическая.

В результате теоретической подготовки, обучаемые должны получить достаточно глубокие и прочные знания об управляемом объекте, принципах построения и логике функционирования его систем, о физических законах, определяющих взаимодействие управляемого объекта с другими объектами и внешней средой, о динамических характеристиках и возможностях объекта, об органах управления и контроля, о методах управления объектом в различных ситуациях.

В результате профессиональной практической подготовки формируются необходимые умения и навыки, которые позволяют оператору уверенно осуществлять управление экипажами в простых, сложных и критических ситуациях.

В связи с повышением требований к качеству подготовки диспетчеров управления воздушным движением в условиях снижения интенсивности полетов и длительных перерывах в управлении экипажами самолетов наиболее эффективным средством профессиональной подготовки являются тренажеры, использование которых в учебном процессе обеспечивает максимальную эффективность при минимальных затратах.

Повышение эффективности использования тренажеров - большая комплексная проблема, решение которой зависит от целого ряда факторов [5].

Однако можно выделить два основных направления этой работы - совершенствование и внедрение в учебный процесс технических средств обучения операторов и развитие математического и программного обеспечения тренажеров и совершенствования методического обеспечения их использования (рис. 1).

При этом на этапе создания тренажеров необходимо однозначно ответить на следующие вопросы: чему учить оператора; какая методика должна применятся для его обучения; какие технические средства должны применятся в тренажерах.

Рациональное построение тренажерных комплексов требует применения специальных технологий, обеспечивающих информационное, аппаратное и программное сопряжение тренажных средств, многократное, экономически рентабельное использование ресурсов, возможность постоянной модернизации тренажеров и расширение их состава.

Тренажёр должен обеспечивать идентичность восприятия информации и пространственновременных характеристик управляющих воздействий обучаемого на тренажере и на реальном объекте, широкий диапазон воспроизводимых в тренировочных упражнениях условий и ситуаций, гибкую перестройку на выполнение различных задач.

Выполнение указанных задач и требований обеспечивается соответствующим структурным построением тренажёра (рис. 2). 


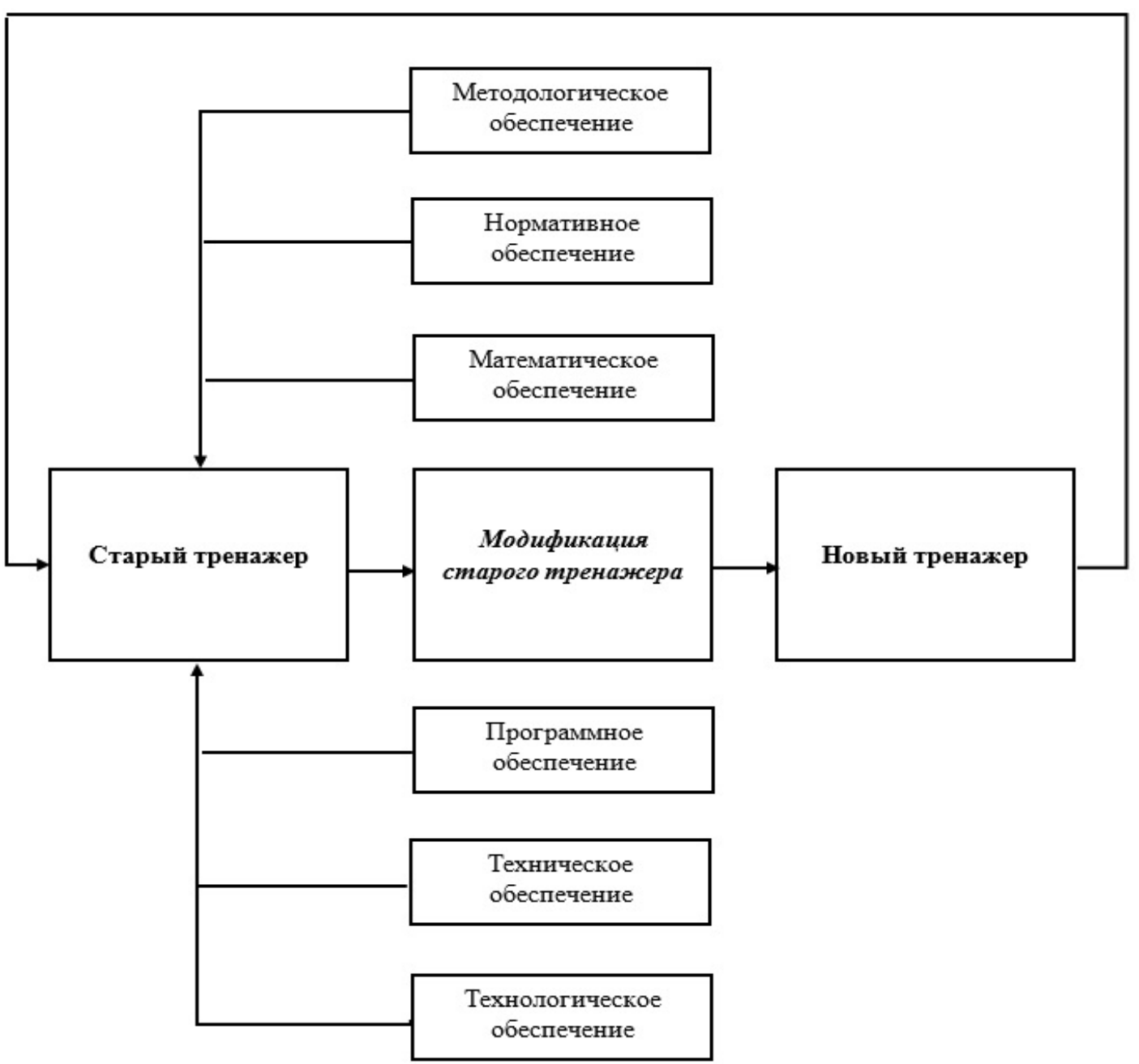

Рис. 1. Методологические основы модификации тренажерных комплексов

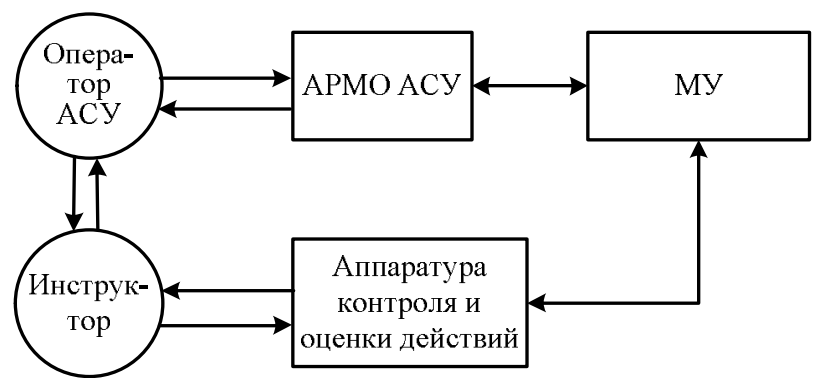

Рис. 2. Структура тренажера

С учетом наиболее существенных задач, которые должны быть реализованы на тренажере, его можно представить как систему, состоящую из оператора АСУ, автоматизированного рабочего места оператора АСУ (АРМО АСУ), моделирующего устройства (МУ), аппаратуры контроля и оценки действий обучаемых (АКОД) и инструктора, а также связей между ними. Основным элементом тренажёра является автоматизированное рабочее место оператора (АРМО) АСУ. На нём воссоздаются условия имитируемого процесса. АРМО АСУ представляет собой выполненный в натуральную величину макет рабочей зоны реального объекта или сам реальный объект. На АРМО устанавливаются все необходимые органы управления, средства отображения и средства связи, которыми пользуется оператор при управлении реальным объектом.

В качестве моделирующего устройства (МУ) используется, как правило, вычислительная система (ВчС). На основе программно реализуемой модели объекта и его систем рассчитываются параметры, необходимые для имитации условий протекания реального процесса. Эти параметры выводятся на средства отображения АРМО АСУ.

\section{Выводы}

Поддержание профессионально важных качеств и их восстановление при помощи тренажерной подготовки - это один из основных видов подготовки диспетчеров управления воздушным движением, который позволяет закреплять и углублять полученные знания и приобретать навыки в управлении экипажами в сложных ситуациях.

От того, насколько продумана такая подготовка и насколько хорошо продуман и проведен процесс обучения зависит уровень профессионального мастерства и безопасности полетов.

Указанные обстоятельства вызывают необходимость унификации проведения тренажерной подготовки на всех уровнях, начиная от учебного заведения заканчивая местом постоянной службы или работы специалиста. В процессе подготовки должен 
предусматривается постоянный контроль действий операторов, в том числе процесс восприятия ситуации оператором, его осмысливания, формирования необходимых навыков, а также психофизиологического состояния оператора при решении им поставленной задачи.
Дальнейшие исследования необходимо направить на создание и обоснование единой методологии построения тренажерных комплексов для обучения диспетчеров управления воздушным движением на основе использования новых информационных технологий.

\section{СПИСОК ЛІТЕРАТУРИ}

1. Неделько С. П. Разработка системы критериев оценки для автоматизированного анализа действий авиадиспетчеров па тренажерах обслуживания воздушного движения / С. Н. Неделько, В. А. Григорецкий, А. С. Паленный / Наукові праці академії, - вип. IX / за ред. Р. М. Макарова - Кіровоград: ДЛАУ, 2005. - 387 с.

2. Біла книга національної освіти України / Акад. пед. наук України; за ред. В. Г. Кременя. - К., 2009. - 185с.

3. Паленный А. С. Разработка алгоритма автоматизированной оценки действий авиадиспетчеров на тренажерах обслуживания воздушного движения / А. С. Паленный // Наукові праці академії - вип. ХI / за ред. Р. М. Макарова - Кіровоград: ДЛАУ. - 2006. - С 118-130.

4. Санников В. А. Методика оценки уровня знаний специалистов УВД и автоматизированных систем контроля // Псих. пробл. повышения работоспособности летного и диспетчерского состава ГА : Межвуз. тем. сб. науч. тр. - СПб., 2000.

5. Шукшунов В. Е., Бакулов Ю. А., Григоренко В. Н. Тренажерные системы. - М.: Машиностроение, 1981. - 256 с.

6. Тренажерные комплексы и тренажеры : технологии разраб. и опыт эксплуатации / [В. Е. Шукшунов, В. В. Циблиев, С. И. Потоцкий и др.]; под ред. В. Е. Шукшунова. - М. : Машиностроение, 2005. -383 с.

7. Кадочников А. И. Формирование навигаторской компетентности курсантов в процессе тренажной подготовки // Образование и самообразование. - Казань: КГПУ, 2008. - № 3 (9). - С. 93-102.

8. Красовский А. А. Основы теории авиационных тренажеров. М.: Машиностроение, 1995. - 304 с.

9. Автоматизированные обучающие системы профессиональной подготовки операторов летательных аппаратов / Л. С. Демин, Ю. Г. Жуковский, А. П. Семенихин и др. / под ред. В. Е. Шукшунова. М.: Машиностроение, 1986. - 240 с.

10. Костылев И.И. Тренажерно-обучающая подготовка судовых специалистов / И.И. Костылев, Н.И. Денисенко, В.А. Петухов // Эксплуатация морского транспорта. - СПб., 2005. - Вып. 44. - С. 31-37.

Рецензент: д-р техн. наук, проф. М. А. Павленко, Харківський національний університет Повітряних Сил імені Івана Кожедуба, Харків Received 15.06.2018

Accepted for publication 12.09.2018

\section{Проблеми підготовки диспетчерів управління повітряним рухом В. С. Сторчак}

Мета статті. Визначення напрямків підвищення ефективності професійної підготовки диспетчерів управління повітряним рухом. У статті розглянуто проблеми професійної підготовки диспетчерів управління повітряним рухом. Обгрунтовується актуальність професійної підготовки та напрямки ії реалізації. Аналізується професійна діяльність та стан професійної підготовки диспетчерів управління повітряним рухом. Визначаються напрямки підвищення ефективності базової професійної підготовки, вдосконалення та відновлення навичок в управлінні екіпажами при виконанні польотів в різних умовах. Пропонується новий підхід до підготовки диспетчерів управління повітряним рухом заснований на використанні нових підходів до побудови та використання тренажерних комплексів та систем. Висновки. Від того, наскільки продумана така підготовка і наскільки добре продуманий і проведено процес навчання залежить рівень професійної майстерності та безпеки польотів. У процесі підготовки повинен передбачається постійний контроль дій операторів, в тому числі процес сприйняття ситуації оператором, його осмислення, формування необхідних навичок, а також псіхофізіологічного стану оператора при вирішенні їм поставленого завдання. Подальші дослідження необхідно спрямувати на створення і обгрунтування єдиної методології побудови тренажерних комплексів для навчання диспетчерів управління повітряним рухом на основі використання нових інформаційних технологій.

Ключові слова: АСУ, оператор, диспетчер УПР, тренажер, підготовка.

\section{Problems air traffic controller training}

\section{Storchak}

The purpose of the article. Determination of directions for increasing the effectiveness of the professional training of air traffic controllers. The article deals with issues related to the feature of training air traffic controller. Actuality of professional preparation and direction of her realization is grounded. Professional activity and state of professional preparation of controllers of air traffic control are analysed. Directions of increase of efficiency of base professional preparation, improvement and renewal of management skills, are certain by crews at implementation of flights in different terms. A new approach to the training of air traffic controller based on the use of new approaches to the construction and use of the training complexes and systems. Conclusions. The level of professional skill and flight safety depends on how well this training is thought out and how well the training process is thought out and conducted. In the process of preparation, it is necessary to provide continuous monitoring of the actions of operators, including the process of perception of the situation by the operator, his comprehension, the formation of necessary skills, as well as the psychophysiological state of the operator when solving his assigned task. Further research should be directed to the creation and justification of a unified methodology for constructing training complexes for training air traffic controllers through the use of new information technologies.

Keywords: ACS, operator, air training controller, trainer, training. 